\title{
Research on the Externality of Wind Power Integration
}

\author{
Qingshan Zhao ${ }^{1}$, Xiaojun $\mathrm{Li}^{1}$, Zhong Fang ${ }^{1}$, Wenjun Gong ${ }^{1}$, Zhongming Zhang ${ }^{1}$, \\ Ming Zeng ${ }^{2}$, Jinghui Sun ${ }^{2,}$, and Shicheng Wang ${ }^{2}$ \\ ${ }^{1}$ State Grid Xinjiang Electric Power Company, Xinjiang 830002, China \\ ${ }^{2}$ School of Economic and Management, North China Electric Power University, Beijing, 102206, \\ China \\ asjhcinderella@163.com
}

Keywords: Wind power integration, environmental benefits, positive externality, negative externality

\begin{abstract}
With the problem of "wind power curtailment" getting increasingly serious, wind power integration has been faced with a big challenge. Therefore, to study its externality integration quantitatively can not only guide the scientific development of wind power industry, but also lay a foundation to formulate the compensation incentive mechanism for related stakeholders. Aiming at each interest body, this paper studies external benefits and costs of wind power integration, builds a relatively perfect quantitative research system for the externality of wind power integration, and puts forward the calculation methods for external effects for all bodies, which provides theoretical support for decision makers to establish the compensation mechanism and pricing strategy for wind power integration.
\end{abstract}

\section{Introduction}

Recently, with the growing demand of electricity, wind power generation technology is applied worldwide. Compared with fossil energy, wind power has advantages of rich resource reserve, little environmental pollution and low operating cost, which promotes environmental protection and energy conservation. Therefore it is an effective way to address the climate change and maintain the safe and economic operation of power system. However, due to the intermittency and volatility of wind power output, the integration can also produce negative externalities, hindering the economic and social benefits of power system ${ }^{[1]}$. The existence of negative externalities will discourage relevant stakeholders from accepting wind power integration ${ }^{[2]}$. Therefore, to identify and analyze the multiple externalities of wind power integration will help guide the reasonable evaluation of the external value of wind power generation and determine the size of grid-connected wind power.

Current researches on the externalities of wind power integration include positive and negative externalities ${ }^{[3-6]}$. In terms of positive externalities, researches focus on emissions reduction ${ }^{[7-8]}$ and social benefits ${ }^{[9-11]}$. In terms of negative ones, researches include the increasing purchasing cost, construction cost and reserve capacity of grid companies ${ }^{[12-13]}$, increasing start-up and maintenance cost of thermal power plants ${ }^{[14]}$, etc. It can be seen that current studies on the externalities of wind power integration are mainly qualitative evaluation, and the quantitative researches focus on positive externalities. Therefore, this paper constructs a comprehensive evaluation system for different stakeholders of wind power integration, and presents measurement methods of externalities, contributing to the establishment of corresponding compensation incentive mechanism.

\section{Externalities Analysis of Wind power Power integration}

Wind power integration has both positive and negative externalities. Specifically, the benefit body of positive externalities is the environment. While the bearing subjects of negative externalities include power grid enterprises, thermal power plants and power users. 


\subsection{Positive Externalities.}

(1) Energy conservation benefits

Theoretically, wind power is inexhaustible energy, so utilize wind energy to generate power can reduce coal and water consumption. And its energy consumption cost per $\mathrm{kW}$ equals zero, so the substitution of wind power for thermal power will save a lot of coal resources.

(2) Emissions reduction benefits

Because wind power generation may replace part of thermal power generation, thus reduce the consumption of non-renewable fossil fuels, pollutant emissions and water consumption. Eventually, it can effectively reduce the emission cost for thermal power, and bring about good environment benefits.

\subsection{Negative Externalities.}

The negative externalities of wind power integration mainly work for three aspects: power grid enterprises, thermal power enterprises and power users.

(1) Power grid enterprises

Purchasing cost: Though the management approach of generation prices and expenses allocation for wind power has been introduced, acquisition of wind energy has caused bad effects for grid enterprises. Specifically, the benchmarking feed-in tariff of desulfurization coal-fired units is relatively high itself. So if grid enterprises purchase large amount of electricity at high price, it will inevitably increase the average power purchase price.

Construction cost: Most wind power projects are at the tip of power grid in the vast and underdeveloped areas. Due to the high investment and large construction scale of grid-connection projects, power grid has been facing high pressure of construction. Worse still, the decrease of utilization hours of wind power may lengthen the payback period.

Ancillary services cost: To ensure the safe connection of wind power in a large scale, grid enterprises need to arrange lots of spare and load capacity, which will increase the operating cost.

(2) Thermal power enterprises

Operation mode: As grid enterprises give priority to wind power integration, the operation mode of the thermal power units has been changed to take up more peak-shaving task to keep power balance. In order to meet the scheduling requirements, thermal power units function as start-stop and surcharging load, which may then increase fuel cost.

Power generation plans and generation: Due to the limitation of load increment in a certain period, the increase of wind power integration will inevitably reduce the percentage of other power supply.

Maintenance cost: Peak-load modulation through start-stop and surcharging load take long to input parameters and operate equipment, thus increasing the likelihood of accidents.

(3) Power users

The cost of electricity use: The integration will also increase operation and maintenance costs of power grid enterprises. These effects may be manifested by high selling price of electricity

Power quality: Because of the instability of wind power, it will hinder system safety and reliable operation. Power quality deterioration will bring huge economic losses to users, including electric power consumption, equipment damage, and recovery cost of customer production, etc.

\section{The Externalities Calculation Model of Wind power Integration}

According to the analysis before, select indicators that are important, quantifiable, establish the externalities calculation model of wind power integration for related subjects, and then quantitatively assess the externalities of wind power integration.

\subsection{Power Grid Enterprises.}

The effects of wind power integration on the power grid enterprises are mainly manifested in two aspects: increasing power purchasing cost and construction cost.

(1) Increasing purchasing cost 
State requires wind power be fully connected to the grid, so the grid companies will purchase wind power to replace part of thermal power.The difference between the power purchasing prices increases the purchasing cost, as shown in equation (1):

$$
E_{1}=Q_{g w} \bullet p_{g w}-Q_{g w} \bullet p_{g t}=Q_{g w}\left(p_{g w}-p_{g t}\right)
$$

Where, $E_{1}$ is electricity purchasing cost increment; $Q_{g w}$ is purchasing power; $p_{g w}$ is the average purchasing price for wind power; $p_{g t}$ is the purchasing price for thermal power.

(2) Increasing construction cost

Power grid enterprises recover the construction capital of wind power access projects through purchasing wind power. The annual profit of purchasing wind power is shown as follows:

$$
Y_{W}=R_{W}-C P_{W}=p s \times Q_{s w}-p_{w} \times Q_{p w}
$$

Set the average line loss rate as $r$, then:

$Q_{S W}=Q_{P W}(1-r)$

$Y_{W}=Q_{P W}\left[p s(1-r)-p_{w}\right]$

Where $Y_{W}$ and $C P_{W}$ are annual profit and cost of purchasing wind power separately; $R_{W}$ is annual income of selling wind power; ps is average selling price; $Q_{S W}$ is annual sales of wind power; $P_{W}$ is average feed-in tariff of wind power; $Q_{P W}$ is annual wind power purchased.

Assume the capital of wind power access project needed to be recovered is same every year. The costs needed to be recovered every year include two parts: one is the cost charged back yearly converted by one-off construction investment, including construction cost, equipment and project management expense, etc. The other is the annual cost of production and maintenance, including wages and additional wages, equipment operating cost and business expense, etc.

According to the calculation method of equivalent annual worth, consider equipment residual value, we can get:

$$
D=P(A / P, i, n)-F(A / F, i, n)
$$

Where $\mathrm{D}$ is expected annual cost for investment recovery; $\mathrm{P}$ is construction investment cost; $\mathrm{F}$ is residual value; (A/P, I, n) is an equal command capital recovery factor, calculation period is $n$ and calculation interest is $\mathrm{i}$; (A/F, I, n) is matching coefficient of sunk fund, calculation period is n, and calculation interest is $\mathrm{i}$; $\mathrm{N}$ is average payback period.

Assume annual production maintenance cost is $\mathrm{C}$, so the loss of wind power access projects can be calculated as follows:

$$
E_{2}=D+C-Y_{W}=P(A / P, i, n)-F(A / F, i, n)+C-Q_{P W}\left[p s(1-r)-p_{W}\right]
$$

\subsection{Conventional power generation enterprises.}

The externalities of wind power integration for conventional power generation enterprises mainly reflect in operating cost, power generation and maintenance cost, etc.

\subsubsection{Operating cost.}

Thermal power generators have to conduct peak shaving for wind power power by load reduction or start-stop, which will increase units operation cost.

(1) Load reduction

Thermal power generators perform peak-load modulation by load reduction will increase the cost of coal consumption. For example, suppose that the sum of the power of wind farm is $\mathrm{P}_{\mathrm{W}}$, all the power is assumed through load reduction by thermal power generators from 1 to $n(n \geqslant l)$. So the extra coal consumption involved in load reduction can be calculated by comparison as follows:

$$
\begin{aligned}
& E_{31}=\sum_{i=1}^{n} p_{i w}\left(b_{i w}-b_{i 0}\right) \tau \times 10^{-3} \\
& p_{i 0}=p_{i w}+P_{w} \bullet \frac{N_{i}}{\sum N_{i}}
\end{aligned}
$$

Where $p_{i 0}$ is the output of thermal power generator i with no wind power integration; $p_{i w}$ is the output of thermal power generator with wind power integration; $E_{31}$ is the lost coal quantity caused 
by thermal power operation with wind power integration; $b_{i w}$ is the coal consumption rate of power supply corresponding to the output $p_{i w}$ of thermal power generator $\mathrm{i}$ with wind power integration; $b_{i 0}$ is the coal consumption rate of power supply corresponding to the output $p_{i 0}$ of thermal power generator i without wind power integration; $\tau$ is operation duration of wind power integration.

(2) Start-stop

When thermal power generators cannot realize power balance through load reduction, sometimes it needs start-stop peak shaving of thermal power units after wind power integration. Suppose that the sum of the power of wind farm is assumed through generators start-stop by thermal power generators from 1 to $m(m \geq 1)$.

Affected by wind power integration, start-stop times of thermal power unit $\mathrm{j}(\mathrm{j}=1, \mathrm{~L}, \mathrm{~m})$ are $M_{j}$, in which $\mathrm{m}$ and $M_{j}$ are determined by wind power curve $P_{w}$. The start-stop cost of each unit is as follows:

$$
C_{j}=F_{j} \bullet M_{j}
$$

Where: $F_{j}$ is the start-stop cost of generator $\mathrm{j}$; $M_{j}$ is the start-stop times of generator $\mathrm{j}$.

The total losses of start-stop are the sum of the cost of each generator, namely,

$$
E_{32}=\sum_{j=1}^{m} C_{j}=\sum_{j=1}^{m} F_{j} \bullet M_{j}
$$

(3) Combine load reduction and generators start-stop

With the massive integration of wind power, it's not enough to depend on load reduction only. In fact, when $P_{\text {iw }}+P_{W} \bullet \frac{\mathbb{N}_{\mathrm{f}}}{\sum \mathbb{N}_{\mathrm{f}}} \geq N_{\overline{\mathrm{i}}}$, it is necessary to add some start-stop of thermal power generators to consume wind power.

After considering the start-stop of thermal power generators, modify equation (8):

$$
p_{i 0}=p_{i w}+\left(P_{W}-\sum_{j=1}^{m} p_{j w}\right) \bullet \frac{N_{i}}{\sum N_{i}}
$$

Where $\mathrm{m}$ is the number of thermal power generators involved in start-stop; $\mathrm{N}$ is the number of thermal power generators involved in load reduction.

Using $b_{i 0}$ in equation (11) to solve equation (7), the loss of thermal power generator is:

$$
E_{33}=E_{31}+E_{32}
$$

\subsubsection{Power generation plans and generation.}

Thermal power generators take the tasks of peak shaving and frequency modulation, leading to the reduction in their own generating electricity, including:

(1) Load reduction for peak shaving

The total generation of thermal power can be calculated by equation $Q_{W}=\int P_{W}(t) d t$. In this way, the lost power of thermal power generator i can be calculated as follows:

$E_{41 i}=Q_{W} \frac{N_{i}}{\sum N_{i}}$

(2) Start-stop for peak shaving

In this way, the lost power of thermal power generator $\mathrm{j}$ can be calculated as follows:

$E_{42 j}=N_{j} \bullet \tau_{j}$

Where $N_{j}$ is installed capacity of thermal power generators; $\tau_{j}$ is the duration time of thermal power generator $\mathrm{j}$ in one cycle.

\subsubsection{Generators maintenance.}

Through researching equipment failure, most of the mechanical equipment failure rate curve is shown in Figure. 2. This curve is often called the bathtub curve. According to this curve, the change in equipment failure rate with time can be divided into early, accidental and wear failure period. 


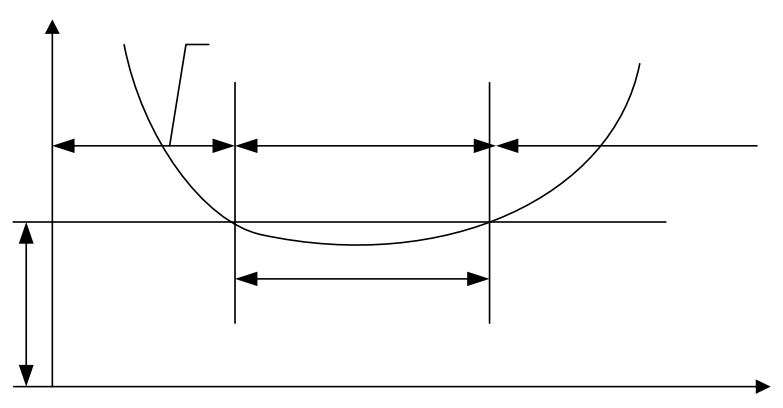

Fig. 1 Equipment failure bathtub curve

As shown in Figure 2, the equipment failure mainly occurs in the early and late period. Assuming that wind power grid, thermal power generators go on A level maintenance $M_{C}$ times, B level maintenance $M_{D}$ times, C level maintenance $M_{E}$ times in the first decade; and A level maintenance $M_{U}$ times, B level maintenance $M_{V}$ times, C level maintenance $M_{W}$ times in the last decade. The losses caused by increasing maintenance times of thermal power generators can be calculated by the following equation:

$$
E_{5}=\left(M_{C}+M_{U}\right) P_{A}+\left(M_{D}+M_{V}\right) P_{B}+\left(M_{E}+M_{W}\right) P_{C}
$$

Where $P_{A}$ is the average cost of thermal power generators for A level maintenance; $P_{B}$ is the average cost of thermal power generators for $\mathrm{B}$ level maintenance; $P_{C}$ is the average cost of thermal power generators for $\mathrm{C}$ level maintenance.

\subsection{Power users.}

Wind power integration may increase electricity cost. According to the current policy, the extra part of the feed-in tariff of renewable energy power surpassing local desulfurization coal-fired units, can be recovered by renewable energy additional electricity price. And this price can be included in the electricity sales price of power grid enterprises, and then the grid enterprises charge to power users. Therefore, the extra part can be used to measure the increment of electricity cost:

$$
E_{6}=\left(P_{o g}-P_{\text {fog }}\right) \times Q_{\text {cons }}
$$

Where $E_{6}$ is the electricity cost increment in user side; $P_{\text {og }}$ is feed-in tariff of wind power; $P_{f \circ g}$ is feed-in tariff of local desulfurization coal-fired generators; $Q_{\text {cons }}$ is power consumption.

\subsection{Environment.}

(1) Energy conservation

As discussed ablve, improving the proportion of wind power can effectively reduce fuel cost. The resources conservation value $E_{7}$ of wind power can be measured by the economic value of coal and fuel oil consumed, which are used to produce the same amount power. In coal consumption, for example:

$$
E_{7}=P_{C} \times M_{C}=P_{C} \times G_{W} \times b \times 10^{-6}
$$

Where $P_{C}$ is the average market price of plant coal; $M_{C}$ is the saving coal quantity of wind power; $G_{W}$ is annual generation of wind farm; b is average coal consumption rate.

(2) Emissions reduction

Wind power generation instead of thermal power can reduce the conbustion of fossil fuels, thereby it reduces pollutant emissions, such as $\mathrm{CO}, \mathrm{SO}_{\mathrm{x}}, \mathrm{NO}_{\mathrm{x}}, \mathrm{CO}_{2}$, particulates, fly ash and slag, etc. Therefore, mitigation benefits can be shown through the following equation:

$$
E_{8}=\sum_{i=1}^{n} V_{i} \bullet \Delta Q i=\sum_{i=1}^{n} V_{i} \bullet q_{i} \bullet M_{c}
$$


Where $E_{\mathrm{g}}$ is mitigation benefits of wind power generation; $V_{i}$ is environmental value of the pollutant item $\mathrm{i} ; \Delta Q_{i}$ is emissions reduction of the item $\mathrm{I} ; q_{i}$ is single pollutant emission rate of coal-fired power plants; $M_{C}$ is the saving coal quantity of wind power.

\section{Conclusion}

Through the analysis, wind power generation has the advantages of energy saving and emissions reduction. But meanwhile, it brings negative externalities to power grid enterprises, thermal power plants and power users. By combing the positive and negative externalities of wind power integration, this paper puts forward the calculation methods of externalities related to different stakeholders, which provides the reference for decision makers to determine the compensation mechanism for bearing subjects of negative externalities. Moreover, it helps improve the enthusiasm of each subject to accept wind power integration, and promote the sustainable development of wind power industry in China.

\section{References}

[1] Fang Yiping. Economic Welfare Impacts From Renewable Energy Consumption: the China Experience[J]. Renewable and Sustainable Energy Reviews, 2011, 15(9): 5120-5128.

[2] Xiao Yu, Hang Qu. Wind Power in China-Opportunity goes with Challenge[J]. Renewable and Sustainable Energy Reviews, 2010, 14(8): 2232-2237.

[3] Zhang Guangchao. Research on the Externality of Wind Power Integration[D]. Beijing: North China Electric Power University, 2011.

[4] Li Hongze, Zhao Huiru, Wang Bao, etc. Measurement on External Value of Grid-connected Wind Power Generation[J]. Modern Electric Power, 2012, 29(4): 83-88.

[5] Jurgen Meyerhoff, Cornelia Ohl, Volkmar Hartje. Landscape Externalities from onshore Wind Power[J]. Energy Policy, 2010, 38(1): 82-92.

[6] Ma Junjie, Zhang Xin, Wang Enqi, etc. Comprehensive Evaluation Model of Grid-Photovoltaic[J]. Water Resources and Power, 2011, 29(6): 169-171.

[7] Zhu Ke-ding, Song Yihang, Tan Zhongfu, etc. China Wind Power Integration Status Quo and Its Benefits to Energy Saving and Emission Reduction[J]. Electric Power, 2011, 44(6): 67-70+77.

[8] Li Hongze, Guo Sen, Wang Bao. Analysis on Environmental Value of Wind Power in China[J]. Energy Technology and Economics, 2011, 23(7): 35-39.

[9] Zhang Jianhui, Wu Rui. The Evaluation Study of the Social Benefits of Wind Farm Investment Project[J]. Value Engineering, 2011(5): 33-34.

[10] Yan Jianwen, Xu Chuanzhao, Wen Weizhong. Social Evaluation of Wind Power Construction Project Based on Fuzzy Multitier Comprehensive Assessment[J]. Journal of Xi'an University of Technology, 2011, 27(2): 234-238.

[11]Zeng Ming, Li Hong-dong, FAN Yan-xia. Study on Wind Power Social Benefits Evaluation Model and Its Application[J]. Power DSM, 2009, 11(5): 17-19.

[12]Zhang Feng. Influence and Countermeasures of Renewable Power Generation on Power Grid Operation[J]. Zhejiang Electric Power, 2010(3): 9-11+50.

[13]Tian Hong, Chen Xinglong, Wang Lei, etc. Research on External Costs Impact of Wind Power Integration on Power Grid Enterprises[J]. Business Culture, 2010(6): 131-132.

[14]Zhou Lisha. Research on the Evaluation and Comprehension Policies of the External Economy of Wind Power Project Based on ANP-Fuzzy[D]. Beijing: North China Electric Power University, 2009. 